\title{
Comparison of non-assisted versus head and tail rope- assisted recovery after emergency abdominal surgery in horses
}

\author{
Martina Rüegg ${ }^{7}$, Regula Bettschart-Wolfensberger ${ }^{7}$, Sonja Hartnack ${ }^{2}$, Hannah K. Junge ${ }^{7}$, Felix Theiss ${ }^{7}$ and Simone K. Ringer ${ }^{l}$ \\ ${ }^{1}$ Equine Department, Vetsuisse Faculty University of Zurich, Zurich, Switzerland \\ 2 Section of Epidemiology, Vetsuisse Faculty, University of Zurich, Zurich, Switzerland
}

\begin{abstract}
Summary: The objective of this study was to compare anaesthetic recoveries without assistance (group NA) to a head and tail rope-assisted technique (group A) after emergency abdominal surgery in horses. Additionally, possible risk factors for the quality of recovery (S: safe, NS: non-safe) were investigated and possible complications associated to the head and tail rope technique recorded. For that purpose 200 anaesthetic protocols (100 NA, 100 A) from horses that all received a standardised medetomidine-isoflurane balanced anaesthesia regime and medetomidine in combination with morphine for recovery were analysed retrospectively. No significant difference regarding recovery score was detected between NA and A horses. Fatalitalities (3/100 in each group) were similarly distributed between groups. However, in group NA only one horse died because of trauma during recovery. The other two horses died before attempting to stand up. All 3 horses that died in group A were euthanized because of trauma. Hypoxemia (defined as arterial oxygen partial pressure $<60 \mathrm{mmHg}$ ) during anaesthesia was a risk factor for non-safe recoveries. No influence was detected for age, weight, duration of general anaesthesia, reason of colic surgery, recovery technique $(A, N A)$, hypotension during anaesthesia, time in lateral recumbency, time in sternal recumbency and time until standing. Several technical complications (material fail, twisting of ropes, halters slipping off and loss of ropes) were observed using the head and tail ropes, probably being partially responsible for the unexpectedly high number of dangerous and fatal recoveries observed in group A. The present study could not demonstrate that the head and tail rope technique can reduce fatalities or improve anaesthetic recovery scores after emergency abdominal surgery in horses. Hypoxemia during general anaesthesia increases the risk of non-safe recovery.
\end{abstract}

Keywords: recovery, head and tail rope, horse, colic surgery, general anaesthesia

Citation: Rüegg M., Bettschart-Wolfensberger R., Hartnack S., Junge H. K., Theiss F., Ringer S. K. (2016) Comparison of non-assisted versus head and tail rope-assisted recovery after emergency abdominal surgery in horses. Pferdeheilkunde 32, 469-478

Correspondence: Dr. Simone K. Ringer, Section Anaesthesiology, Equine Department, Vetsuisse Faculty, University of Zurich, Winterthurerstrasse 258c, 8057 Zürich, Switzerland; E-mail: sringer@vetclinics.uzh.ch

\section{Introduction}

General anaesthesia in horses is associated with a higher risk of morbidity and mortality than in other species (Dugdale and Taylor 2016). Johnston et al. (2002) noted cardiac arrest or post-operative cardiovascular collapse, fractures and myopathies as leading causes for mortality. Therefore, the recovery is a critical and also poorly predictable phase (Liechti et al. 2003, Clark-Price 2013). The horse's flight behaviour is regarded as a major risk during recovery, often being responsible for premature attempts to stand (Liechti et al. 2003, Driessen 2006, Wilderians 2008). Furthermore it is assumed, that prolonged recumbency can cause poor muscle perfusion and nerve damage in horses (Liechti et al. 2003, Hubbell 2005). Moreover, the depressant effects of the anaesthetic agents on mental, proprioceptive and motor function may lead to problems in coordination while getting up (Liechti et al. 2003, Driessen 2006). Consequently, premature attempts to rise together with insufficient coordination and muscle or nerve weakness will result in unsuccessful efforts to stand and a high risk of injury (Liechti et al. 2003, Hubbell 2005). Dugdale et al. (2016) remarked, that recovery quality in horses with ASA status 3 and 4 was associated with significantly worse recoveries. Therefore, in patients with higher risk of postanaesthetic complications, it seems reasonable to assist the recovery (Del Castillo and Matthews 2005, Wagner 2009). These "high-risk-patients" include horses undergoing emergency abdominal surgery in which the risk of mortality is increased (Dugdale and Taylor 2016). In recent years a num- ber of techniques has been developed to assist recovery after general anaesthesia (Muir and Hubbell 2009). Assistance using head and tail ropes is probably the most commonly used method (Kaestner 2010). However, to our knowledge studies comparing recovery without assistance to recovery with head and tail ropes in horses undergoing emergency abdominal surgery are lacking.

At the Vetsuisse Faculty Zurich horses undergoing colic surgery recovered without assistance for many years. In 2012 , as a consequence of several fatalities, it was decided to assist all colic horses with head and tail ropes from then onward. The objective of this study was to retrospectively compare non-assisted with head and tail rope-assisted recoveries after emergency abdominal surgery, with special regard to the quality of recovery. Possible complications associated with the head and tail rope system were recorded. Additionally, possible risk factors for quality of recovery were investigated. We hypothesized that the quality of recovery after emergency abdominal surgery in horses can be improved by assisted recovery using head and tail ropes.

\section{Material and methods}

For this study anaesthesia protocols of horses undergoing colic surgery at the Vetsuisse Faculty University of Zurich 
in the period from March 2008 to December 2015 were evaluated retrospectively. The horses were grouped in 2 groups; group A (Assisted; $n=100$ ) if they were assisted with head and tail ropes during recovery from general anaesthesia and group NA (Non-Assisted; $n=100$ ) if they were not assisted. Inclusion criteria were emergency colic surgeries. Exclusion criteria were anaesthesia during the previous 12 months, body weight $<200 \mathrm{~kg}$, euthanasia on the surgical table and non functioning video recording during recovery.

\section{Anaesthesia protocol}

In all horses a 14 gauge $\times 160$ mm jugular catheter (Secalon $T$ with flowswitch; Becton Dickinson AG, Switzerland) was placed using local anaesthesia with mepivacaine $2 \%$ (Mepivacain HCL $2 \%$; Kantonsapotheke Zurich, Switzerland). The horses were premedicated prior to anaesthesia with penicilIin (Penicillin Natrium Streuli ad us. Vet.; Streuli Pharma AG, Switzerland; 30'000 IE/kg), gentamicin (Genta $100 \mathrm{mg} / \mathrm{ml}$, cp-pharma, Germany; $9 \mathrm{mg} / \mathrm{kg}$ ) and flunixin meglumine (Flunixin ad us. vet.; Biokema SA, Switzerland; $1 \mathrm{mg} / \mathrm{kg}$ ) intravenously (IV), as well as vitamin $E(1 \mathrm{mg} / \mathrm{kg})$ and selen $(0.04 \mathrm{mg} / \mathrm{kg}$ ) intramuscularly (IM) (Tocoselenit ad us. vet.; Dr. E. Graeub AG, Switzerland). All horses received $5-7 \mathrm{ml} / \mathrm{kg}$ of hetastarch (HAES-steril 10\%; Fresenius Pharma Schweiz AG, Switzerland) and $10-20 \mathrm{ml} / \mathrm{kg}$ ringer's lactate (Ringer-Lactat-Lösung; Fresenius Kabi AG, Switzerland) before anaesthesia. If necessary for clinical examination, xylazine (Xylazin Streuli ad us. vet.; Streuli Pharma AG, Switzerland; $0.2-1.1 \mathrm{mg} / \mathrm{kg}$ ) or detomidine (Equisedan ad us. vet.; Dr. E. Graeub AG, Switzerland; $0.01-0.02 \mathrm{mg} / \mathrm{kg}$ ) with or without butorphanol (Alvegesic 1\% forte ad us. vet.; Alvetra u. Werfft GmbH, A-2491 Neufeld/Leitha; 0.05-0.1 mg/kg) IV were used.

For all patients a standardised anaesthesia protocol was used. Medetomidine IV (dosed to effect, to reach deep sedation, with an average of $7 \mathrm{mcg} / \mathrm{kg}$ ) (Dorbene; Dr. E. Graeub AG, Switzerland) was used for sedation prior to induction of anaesthesia. Anaesthesia was induced with ketamine (Narketan 10 ad us. vet.; Chassot AG, Switzerland; $2.2 \mathrm{mg} / \mathrm{kg}$ ) and diazepam (Valium 10mg; Roche Pharma Schweiz AG, Switzerland; $0.02 \mathrm{mg} / \mathrm{kg}$ ) IV. Once recumbent, tracheas were intubated and horses connected to a large animal circle system (LAVC-2000; JD Medical distributing Co., Inc, AZ, USA or 2800C-P; Mallard Medical/AB Medical Technologies Inc., CA, USA). The horses were all allowed to breath spontaneously. Anaesthesia was maintained with isoflurane in oxygen and air (inspired oxygen fraction was adapted depending on pulseoximetry readings and arterial partial pressure of oxygen $\left(\mathrm{PaO}_{2}\right)$. Additionally a constant rate infusion (CRI) of medetomidine $(3.5 \mathrm{mcg} / \mathrm{kg} / \mathrm{h})$ was applied. The horses were infused with ringer's lactate to effect. To support the cardiovascular function a CRI of dobutamine (Dobutrex; Eli Lilly S.A., Switzerland) was administered to effect $(0.75-1.25 \mathrm{mcg} / \mathrm{kg} / \mathrm{min})$. A urinary catheter was placed following anaesthesia induction and was not removed before the horse had recovered from anaesthesia.

If considered necessary, horses received additional $3-7 \mathrm{ml} / \mathrm{kg}$ hetastarch during anaesthesia. In case of suspected endotoxaemia, polymyxine (Polymyxin-B-Sulfat
100 '000 IE/ml; Kantonsapotheke Zurich, Switzerland; $6000 \mathrm{IE} / \mathrm{kg}$ ) was applied IV and in case of an unresponsive endotoxaemic shock hydrocortisone (Solu-CORTEF $500 \mathrm{mg}$; Pfizer AG, Switzerland; 1-2 mg/kg) was administered IV.

\section{Monitoring}

Cardiovascular and respiratory variables were measured continuously using a multiparameter monitor (Datex-Ohmeda Cardiocap/ 5; Anandic AVL, Switzerland). An Electrocardiogram (ECG) was attached and pulseoximetry was conducted continuously. Arterial blood pressures were measured invasively by a 22-gauge catheter (Suflo IV Catheter $22 \mathrm{G} \times 1^{\prime \prime}$; Terumo, Medical Solution GmbH, Switzerland) inserted into the facial or transverse facial artery and connected to a pressure transducer (Pressure Transducer DTX/Plus; Becton Dickinson AG; Allschwil, Switzerland). Respiratory frequency (fR), end-tidal isoflurane concentration ( $P E^{\prime}$ lso), endtidal carbon dioxide tension $\left(\mathrm{PE}^{\prime} \mathrm{CO}_{2}\right)$ and inspired oxygen fraction $\left(\mathrm{FiO}_{2}\right)$ were measured continuously and recorded every five minutes. Qualitative parameters including palpebral reflex, spontaneous blinking, nystagmus and involuntary movements were also noted at a 5 minutes interval. Arterial blood gases and $\mathrm{pH}$ were measured regularly every 30 to 60 minutes using a portable analyser (i-STAT Analyser; Axon Lab AG, Switzerland). Fifteen to 30 minutes before the end of anaesthesia morphine was administered to all horses (Morphin $\mathrm{HCl} 10 \mathrm{mg}$; Sintetica SA, Switzerland; $0.1 \mathrm{mg} / \mathrm{kg}$ ) IM. Phenylephrine $0.15 \%$ (Phenylephrini hydrochloridum; G.Streuli \& Co. AG, Switzerland; $2 \mathrm{ml} / 100 \mathrm{~kg}$ ) was administered into the ventral meatus oft the nasal cavity at the end of the procedure and before transport to the recovery box. Once in the recovery box the horses were sedated with medetomidine $(2 \mathrm{mcg} / \mathrm{kg})$ slowly IV. During recovery oxygen $(15 \mathrm{~L} / \mathrm{minu}$ te) was insufflated via the endotracheal tube or, following extubation, via the ventral meatus. The horses were extubated as soon as the swallowing reflex was present or movement occured. For assisted recovery (group A) a rope was fixed to the horses head (halter with rings) and tail. The horses of group NA only got a padded head protector. Afterwards everyone left the recovery box and the horses were observed from outside. All horses recovered in the same recovery box with one exception (one horse in group A). The recovery box used has an extent of $15.65 \mathrm{~m}^{2}$, about 4 meters in length, 4.37 meters in width with an octagonal shape (Figure 1). Floor and walls are rubber padded. On two sides of the recovery box are openings where the assistants have access to observe the horses. By the use of rings attached to the roof and walls of the recovery box the horses can be supported with head and tail ropes (Figure 2).

\section{Criteria for evaluation}

As demographic data age, body weight, breed (distributed in groups) and the gender of the horse (mare, stallion, gelding) were noted. As influencing factors of the anaesthesia on recovery the total time of general anaesthesia (from induction to the end of isoflurane), hypotension during anaesthesia defined as YES (at least 15 minutes mean arterial blood pressure $(\mathrm{MABP})<70 \mathrm{mmHg}$ ) or $\mathrm{NO}$, and hypoxemia defined as YES $\left(\mathrm{PaO}_{2}<60 \mathrm{~mm} \mathrm{Hg}\right)$ or $\mathrm{NO}$ were recorded. Horses were grou- 
ped for the primary reason for colic: Group 1: colic of the small intestine without resection, group 2: colic of the small intestine with resection, group 3: colic of the large intestine excluding torsions of the colon, group 4: torsions of the colon and group 5: other reasons for colic (ovariectomy, torsion of spermatic cord, primary gastric impaction, intraabdominal mass, bleeding, proximal enteritis, paralytic ileus, adhesions, evisceration after castration). During recovery the time in lateral- and in sternal recumbency, the total time from disconnection of the anaesthetic to standing and the recovery score were recorded. For group $\mathrm{A}$ and NA all recoveries were scored by the anaesthetist in charge. For group A additionally, video recordings were available of all recoveries. A single observer (MR) re-evaluated those recordings for quality of recovery retrospectively. Those scores were compared to the ones of the anaesthetists in charge. From the retrospective video analyses further complications associated to the head and tail rope system were noted. Special events such as fractures, injuries, falls or loss of ropes were noted as well as any additional medication other than the described standard protocol. The scoring system used was the same for all horses and all anaesthetists (including MR). The quality of recovery was graded on a scale of five with a score of 1 representing the best recovery:

1 Horse capable to stand at the first attempt, minimal ataxia

2 Two attempts needed before standing

3 More than 2 attempts needed before standing, horse remains calm

4 Horse becomes excited during recovery, several attempts, danger of injury

5 Recovery resulting in injury of the horse

\section{Statistical analysis}

The statistical analyses were performed using the software IBM SPSS Statistics Version 21 and GraphPad PRISM 5.0f (http://www.graphpad.com). Data distribution (age, weight, duration of anaesthesia (minutes), time in lateral recumbency, time in sternal recumbency, time to stand) was analysed using Kolmogorov-Smirnov test. The two groups ( $A$ and NA) were compared using a Students t-test preceded by Levene-test for equal variances for parametric data (age) and a Wilcoxon rank sum test for non-parametric data (weight, recovery score, duration of anaesthesia (minutes), time in lateral recumbency,

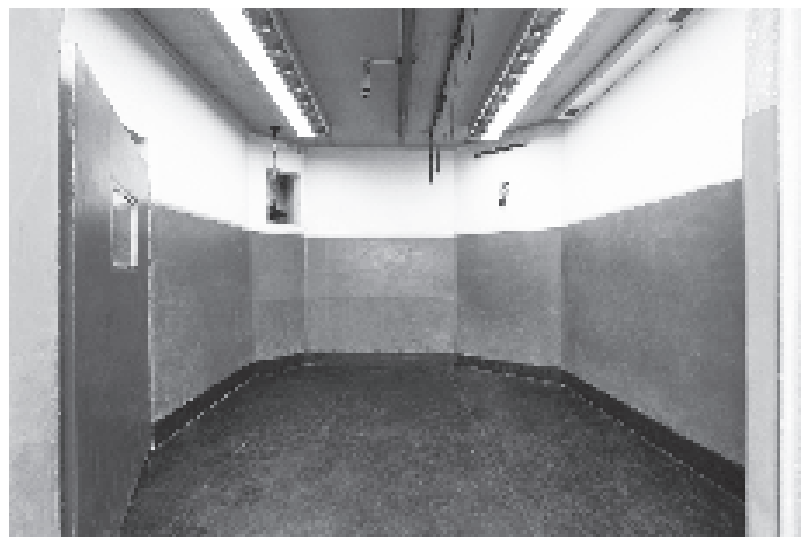

Fig. 1 Lateral view from the entrance of the octagonal shaped, padded recovery box used.

Seitliche Ansicht der verwendeten achteckigen, gepolsterten Aufwachboxe mit Sicht vom Eingang der Box. time in sternal recumbency and time to stand). For further statistical analysis recovery scores were dichotomized into binomial data: safe recovery (S: scores 1-3) and non-safe recovery (NS: scores 4 and 5).

Univariable screening of variables was performed using Student's t-tests (age, anaesthesia duration) or Wilcoxon rank sum test (weight, time in lateral recumbency, time in sternal recumbency and time to stand) for continuous variables to test for their association with the outcome variable (S, NS recovery). Odds ratios (OR) and associated $95 \%$ confidence intervals $(\mathrm{Cl})$ for recovery quality $(\mathrm{S}, \mathrm{NS})$ were estimated for treatment (A vs. NA), hypoxemia (YES/NO) and hypotension (YES/NO). A logistic regression was used to investigate the influence of anaesthesia duration and the effect of group ( $A$, $\mathrm{NA}$ ) on the outcome recovery quality (score). Kappa statistics were used to test interrater (scores recorded in the protocols, scores assessed from videotapes by MR) reliability. Results are presented as mean $\pm S D$, median [IQR] or odds ratio (OR) and associated $95 \%$ confidence intervals $(\mathrm{CI})$ depending on data distribution. Significance was considered when $p<0.05$.

\section{Results}

Completeness of anaesthetic record

In two cases in group NA the recovery score could not be evaluated because the horses died before attempting to stand. Noted blood pressures were incomplete or missing in 8 horses ( 4 in group NA, 4 in group A) and in 4 horses no data on blood gas ( 2 in group NA, 2 in group A) were available and therefore not suitable for further analysis.

Comparison of assisted (A) versus non-assisted (NA) recoveries

There was no difference in age, weight, gender, and breed of horses between A and NA (see Table 1). The two groups did not differ regarding duration of general anaesthesia, the reason for colic surgery and the percentage of horses presenting hypoxemia or hypotension (Table 1). No significant difference was detected between NA and A regarding the recovery score, neither the scores of the anaesthetists in the $A$ group

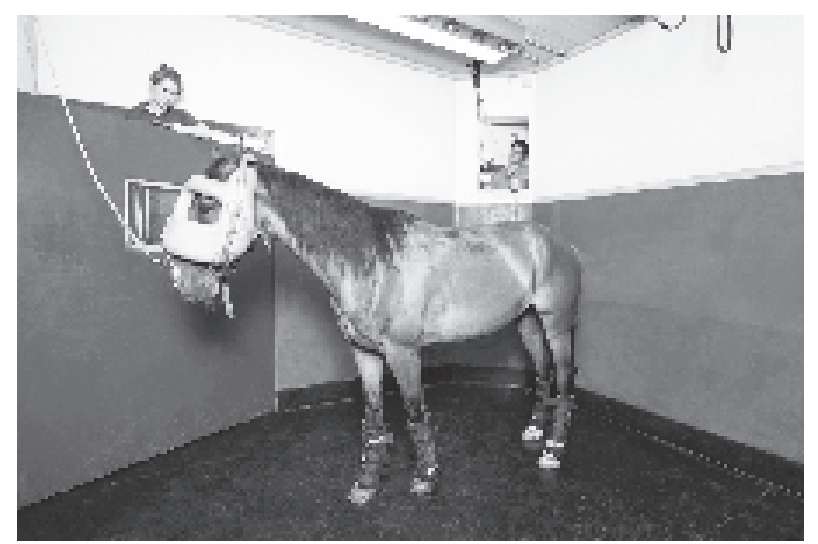

Fig. 2 A horse in the recovery box assisted with head and tail ropes.

Ein Pferd in der Aufwachboxe, welches mit Kopf- und Schweifseil assistiert wird. 
Table I Demographic, anaesthesia, recovery as well as surgery related data of 200 horses, recovering after colic surgery without assistance (NA; $n=100)$ or using a head and tail rope technique $(A ; n=100)$. | Demographische, anästhesie-, aufwachphasen- und operationsrelevante Daten von 200 Pferden, die nicht-assistiert (NA; $n=100)$ oder assistiert mit Hilfe von Kopf- und Schweifseil $(A ; n=100)$ nach Kolikoperation aufgestanden sind.

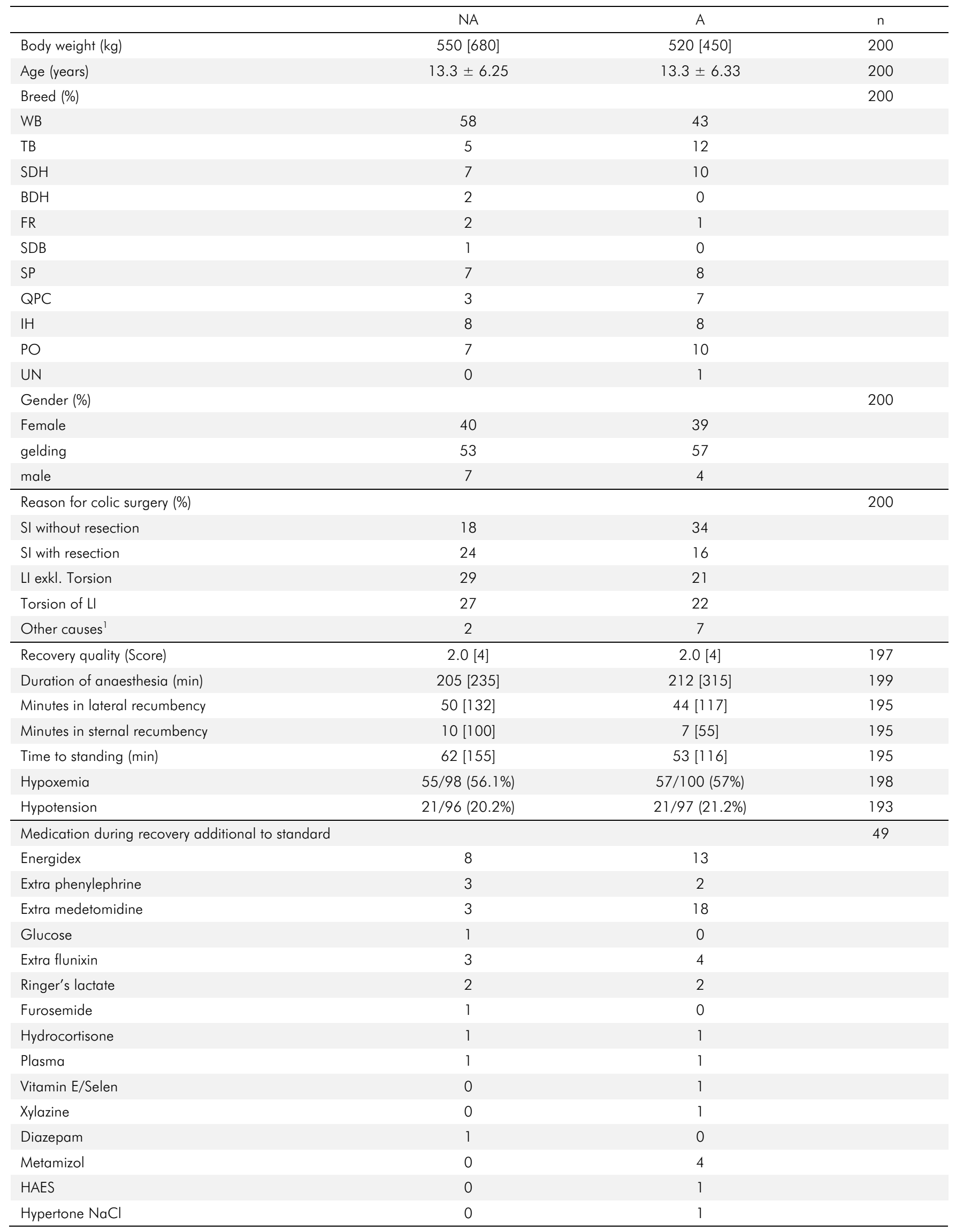


Key for Table 1:

Data presented as Mean \pm SD or median [IQR], significance was considered when $p<0.05$. $n$ : number of horses included; WB: Warmblood; TB: Thoroughbred; SDH: small Draft horses (Freiberger, Haflinger, Fiord); BDH: big Draft horses (Shire Horse, Ardennes); FR: Friesian; SDB: Standardbred; SP: Spanish breed; QPC: Quarter/Paint/Criollo; IH: Icelandic Horse; PO: ponies; UN: unknown; SI: small intestine, LI: large intestine; Medication: additional medication during recovery; 'ovariectomy, torsion of testicle, primary gastric impaction, intraabdominal mass (enlargement of kidney), haemorrhage, proximal enteritis, fluid filled intestine/abdomen, adhesions, evisceration after castration

Die Daten werden dargestellt als Mittelwert \pm Standardabweichung oder Median [Spannweite], ein $p$-Wert $<0.05$ wurde als signifikant bezeichnet n: Anzahl eingeschlossene Pferde. WB: Warmblut; TB: Vollblut; SDH: Leichte Kaltblüter (Freiberger, Haflinger, Fiord); BDH: schwere Kaltblüter (Shire Horse, Ardenner); FR: Friese; SDB: Traber; SP: Spanische Rasse; QPC: Quarter Horse/Paint/Criollo; IH: Islandpferd; PO: Ponys; UN: unbekannt; SL: Dünndarm, LI: Dickdarm. Medication: zusätzliche Medikamente während der Aufwachphase; 'Ovariektomie, Hodentorsion, primäre Magenüberladung, intraabdominale Masse (vergrößerte Niere), Blutung, proximale Enteritis, flüssigkeitsgefüllte Därme/Abdomen, Adhäsionen, Eviszeration nach Kastration

compared to the NA group nor the scores of the author (MR) in the A group to the NA group (Figure 3). There was no evidence of hypotension, hypoxemia and duration of general anaesthesia as a confounding variable. The scores recorded on the protocols in the A group and the scores assessed by the author from the videotapes didn't vary significantly. The interrater agreement was good $(\kappa=0.771 ; 95 \% \mathrm{Cl}(0.58$, 0.96)). The two treatments did not differ regarding the time horses spent in lateral and in sternal recumbency during recovery and the time until standing.
Complications during recovery were seen in 3/100 horses dying or being euthanized during recovery in each group. In group NA, only one horse had to be euthanized because of trauma (humerus fracture) during recovery. The other two horses died before they made any attempt to get up; one after showing seizures and the other one because of respiratory arrest. Another horse in group NA presented seizures and survived following treatment with diazepam. Four horses needed additional manual or rope support because they were unable to stand up without assistance.

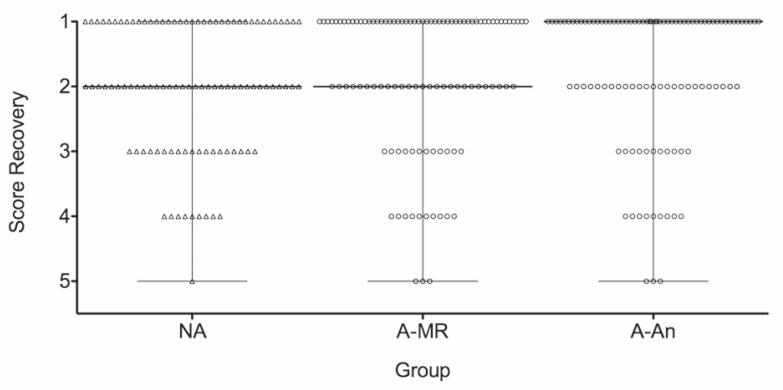

Fig. 3 Distribution of the recovery scores $1-5$ in the non-assisted group (NA), the assisted group assessed by the author (A-MR) and the assisted group assessed by the anaesthetists (A-An)

Verteilung der Qualität der Aufwachscores 1-5 in der nicht-assistierten Gruppe (NA), der assistierten Gruppe beurteilt durch den Autor (AMR) und der assistierten Gruppe beurteilt durch Anästhesisten (A-An).

Table 2 Demographic, anaesthesia, recovery as well as surgery related data of horses presenting a safe recovery $(S=s c o r e ~ 1-3)$ and of horses with a non-safe recovery (NS = score 4 and 5). I Demographische, anästhesie-, aufwachphasen- und operationsrelevante Daten von Pferden mit einer sicheren Aufwachphase (S = Score 1-3) und von Pferden mit einer nicht-sicheren Aufwachphase (NS = Score 4 und 5).

\begin{tabular}{|c|c|c|c|}
\hline & $S$ & NS & $\mathrm{n}$ \\
\hline Body weight $(\mathrm{kg})$ & $530[680]$ & $532.5[230]$ & 200 \\
\hline Age (years) & $13.2 \pm 6.33$ & $14.5 \pm 6.5$ & 200 \\
\hline Reason for colic surgery (\%) & & & 200 \\
\hline SI without resection & 25 & 31.81 & \\
\hline SI with resection & 20.45 & 18.18 & \\
\hline LI exkl. Torsion & 25 & 27.27 & \\
\hline Torsion of $\mathrm{LI}$ & 25 & 18.18 & \\
\hline Other causes ${ }^{1}$ & 5.54 & 4.54 & \\
\hline Duration of anaesthesia (min) & 205 [315] & $247.5[285]$ & 199 \\
\hline Minutes in lateral recumbency & 45 [136] & $56\left[\begin{array}{llllll}1 & 10\end{array}\right]$ & 195 \\
\hline Minutes in sternal recumbency & 10 [100] & $10[50]$ & 195 \\
\hline Time to standing (min) & $57.5[161]$ & $63.5[145]$ & 195 \\
\hline OR for treatment (A/NA) & \multicolumn{2}{|c|}{$1.4(0.55-3.44)$} & 200 \\
\hline OR for hypoxemia (NHX/HX) & \multicolumn{2}{|c|}{$19.6(2.58-148.94)^{*}$} & 198 \\
\hline OR for hypotension (NHT/HT) & \multicolumn{2}{|c|}{$2.4(0.92-6.22)$} & 194 \\
\hline
\end{tabular}

Data presented as Mean \pm SD or median [range] or odds ratio (95\% confidence intervals). Significance was considered when $\mathrm{p}<0.05 ;{ }^{*}: \mathrm{p}=<0.001$; : number of horses included; SI: small intestine, LI: large intestine; A: assisted recovery using head and tail ropes, NA: non-assisted recovery; HX: hypoxemia, NHX: no hypoxemia; HT: hypotension, ' ovarectomy, torsion of spermatic cord, primary gastric impaction, intraabdominal mass, bleeding, proximal enteritis, paralytic ileus, adhesions, evisceration after castration ; NHT: no hypotension; OR: odds ratio

Die Daten werden dargestellt als Mittelwert \pm Standardabweichung oder Median [Spannweite] oder Quotenverhältnis 195\% Konfidenzintervall). Ein $p$-Wert $<0.05$ wurde als signifikant bezeichnet; *: $p=<0.001 ; n$ : Anzahl eingeschlossene Pferde SI: Dünndarm, LI: Dickdarm; A: assistierte Aufwachphase mit Kopf- und Schweifseil, NA: nicht-assistierte Aufwachphase; HX: Hypoxämie, NHX: keine Hypoxämie; HT: Hypotension, 'Ovarektomie, Samenstrangtorsion, primäre Magenüberladung, intraabominaler Tumor, Blutung, proximale Enteritis, paralytischer lleus, Verwachsungen, Darmvorfall nach Kastration, NHT: keine Hypotension; OR: Quotenverhältnis 
In group A, two horses had to be euthanized because of tibia fractures and one horse was euthanized in agony, probably because of a cervical dislocation that occurred as a consequence of rupture of the ring attached to the head rope and a consequent abrupt fall of the horse into the wall of the box. One horse presented seizures during recovery, but survived. Non-life-threatening problems were observed in 4 horses (1 slight myopathy, 1 paresis of the facial nerve, 1 paresis of the radial nerve/triceps myopathy, 1 tooth-fracture and skin/mucosal abrasions). Of the horses that did not survive recovery 2 in each group had been anaesthetised during the night (out of hours) and one in each group during regular working hours. One horse of group $A$ received additional to the standard recovery sedation protocol sedation with medetomidine $2 \mu \mathrm{g} / \mathrm{kg}$ IV when it showed signs of awakening within 10 minutes of an anaesthetic of 6 hours and 20 minutes. Other additional medications applied during recovery are presented in table $\|$ and were similarly distributed between the groups.

Complications associated with the head and tail ropes technique

The horse that died because of a suspected cervical dislocation suffered from a backward fall into the wall after sudden release of the head rope because of failure of the halter-ring. Detachment of the head-rope occurred in another horse without severe consequences. The halter fell off in 3 horses that pulled backwards. The ropes had to be released and refixed because they were twisted around each other in 9 horses. The rope got wrapped around the leg in one of the horses.

\section{Factors influencing recovery (safe versus non-safe)}

Comparing the group of horses with a safe recovery (score 1 3 ) to the group with non-safe recoveries (score 4 and 5) there was no significant difference regarding the age, weight, gender, breed, duration of general anaesthesia, reason for colic, treatment group (NA, A), the time in lateral recumbency, the time in sternal recumbency and the time until standing (Table 2 ). Hypoxemia during general anaesthesia was significantly associated with a non-safe recovery (Table 2 and 3). No influence of hypotension was detected.

\section{Discussion}

The present retrospective study could not show a benefit of assisted recovery from anaesthesia with head and tail ropes after emergency abdominal surgery in horses. Hypoxemia during anaesthesia seems to be a risk factor for non-safe recoveries. The head and tail rope system is the most frequently used technique to assist horses during recovery (Kaestner 2010). This technique is cheaper than other assisted methods, easier to use and provides more security for the personnel compared to manual assistance (Driessen 2006, Wilderians 2008, Muir and Hubbell 2009). Specialists in the field assume that the technique, used by experienced personnel, could reduce the risk associated with recovery (Del Castillo and Matthews 2005, Wilderjans 2008; Bettschart-Wolfensberger 2012). Our study partly supports this hypothesis as two of the three horses in group NA, that suffered from fractures during recovery, were anaesthetised out of hours, when less experienced personnel was available. However overall no differences in recovery quality were detected, when the help with head and tail ropes was compared to non-assisted recovery after colic surgery. This coincides with Auer and Huber (2012) who could not show a clear advantage of head and tail rope-assisted over unassisted recoveries after different types of interventions. Del Castillo and Matthews (2005) noted that the use of head and tail ropes could reduce stumbling and hard falls. However, in our study fatalities occurred in both groups. Despite rope assistance two horses suffered from tibia fractu-

Table 3 Crosstabs showing the relationship of group (NA: non-assisted recovery, A: head and tail rope assisted recovery), hypoxemia and hypotension with quality of recovery (S: safe, NS: non-safe). I Die die Beziehung der Gruppe (NA: nicht-assistierte Aufwachphase, A: assistierte Aufwachphase mit Kopf- und Schweifseil), Hypoxämie und Hypotension mit der Qualität der Aufwachphase (S: sicher, NS: nicht-sicher) aufzeigen.

\begin{tabular}{|c|c|c|c|c|}
\hline & \multicolumn{4}{|c|}{ Score } \\
\hline & & NS & S & total \\
\hline \multirow[t]{3}{*}{ Treatment } & A & 12 (12.1\%) & 87 (87.9\%) & 99 (100\%) \\
\hline & NA & $9(9.1 \%)$ & 90 (90.9\%) & 99 (100\%) \\
\hline & total & 21 (10.6\%) & 177 (89.4\%) & 198 (100\% \\
\hline
\end{tabular}

Score

\begin{tabular}{|c|c|c|c|c|}
\hline & & NS & $S$ & total \\
\hline \multirow[t]{3}{*}{ Hypoxemia } & no & $1(1.2 \%)$ & 84 (98.8\%) & 85 (100\%) \\
\hline & yes & 21 (18.9\%) & 90 (81.1\%) & 111 (100\%) \\
\hline & total & 22 (1 1.2\%) & 174 (88.8\%) & 196 (100\%) \\
\hline
\end{tabular}

Score

\begin{tabular}{ccccc}
\hline & & NS & S & total \\
\hline Hypotension & no & $13(8.7 \%)$ & $136(91.3 \%)$ & $149(100 \%)$ \\
& yes & $8(18.6 \%)$ & $35(81.4 \%)$ & $43(100 \%)$ \\
& total & $21(10.9 \%)$ & $171(89.1 \%)$ & $192(100 \%)$ \\
\hline
\end{tabular}


res and one horse had to be euthanized in agony probably because of a cervical dislocation after a backward fall into the wall. In the authors opinion assistance with ropes might help to stabilize the horse when it is resonably calm, avoiding further falls. This assumption has maybe also led the anaesthetist to more often administer additional sedation in the A group. The net effect was an identical mean recovery score in both groups. Therefore a significant influence of this additonal sedation on outcome seems unlikely. It is simply very difficult to completely prevent heavy, big, agitated horses from falling down again. Furthermore, head and tail-ropes will probably not prevent injuries occurring, when the horse pushes itself up (Bidwell et al. 2007, personal observation).

The use of ropes during recovery is not unproblematic (Driessen 2006). The present study payed special attention to complications occurring using the head and tail rope technique. Material fail, twisting of ropes, halters falling off and loss of ropes were observed. These complications were presumably responsible for part of the non-safe recoveries in group $A$. In the authors opinion the used recovery box is not ideal for rope recovery and this might have contributed to the technical problems. Furthermore, colic surgeries are frequently performed out of hour and therefore recoveries might have been assisted by less experienced persons. We assume that the quality of recovery could be improved with an ideally designed recovery box, high quality and well-maintained material, and only experienced, strong persons with a good understanding of assisting horses.

Comparing the group with safe recoveries (S) to the group with non-safe recoveries (NS) hypoxemia increased the risk for non-safe recoveries. In colic horses the likelihood of hypoxemia is increased because of dorsal recumbency (Steffey et al. 1977) and abdominal distension (Trim et al. 1989). Equine anaesthetists assume that hypoxemia has a negative effect on recovery (Muir and Hubbell 2009). However, to the autho$r^{\prime}$ s knowledge, this is the first study showing a negative effect of hypoxemia on the recovery of anaesthesia after colic surgery. Hypoxemia, especially if combined with reduced perfusion can lead to tissue hypoxia with consequent myopathy and/or neuropathy and therefore negatively influence recovery (Dugdale and Taylor 2016).

Hypotension during general anaesthesia could also predispose to myopathies (Grandy et al. 1987) and horses with myopathy would be expected to present worse recoveries (Richey et al. 1990, Dugdale and Taylor 2016). However, hypotension during anaesthesia was not associated with an increased risk for non-safe recoveries in the present study. This coincides with Young and Taylor (1993) who did not find a correlation of the hypotension index with the quality of recovery.

It's assumed that longer anaesthetic duration negatively influences quality of recovery (Trim et al. 1989, Young and Taylor 1993, Dugdale et al. 2016). However, this could not be confirmed with the present study. Though the mean anaesthesia duration was 205 minutes (group NA) and 212 minutes (group $A$ ), therefore longer than the mean anaesthesia duration of 126 minutes reported by Trim et al. (1989). Early stimulation of the horses during recovery might be detrimental (Del Castillo and Matthews 2005, Bettschart-Wolfensberger 2012). This might be more probable when people are waiting next to the horse to assist recovery. However, time spent in lateral and sternal recumbency, as well as time to standing was not different between the two groups (NA, A). Also no effect on safe or non-safe recovery could be detected depending on duration of recovery. Contrary to Young and Taylor 1993 recovery duration did not affect safety of recovery in the present study. The temperament of the horse is an important factor regarding the quality and duration of recovery (Muir and Hubbell 2009). In our study the two groups (NA, A) had a similar distribution in age, weight, breed and gender but the individual temperament was not specially scored. Also the general condition might influence recovery quality. General condition will vary widely depending on the cause and duration of colic. The reason for colic surgery was similarly distributed in both groups (NA and A). Also, horses presenting a safe recovery did not differ from those presenting non-safe recoveries regarding age, weight and cause of colic.

The main limitation of this study is its retrospective nature. Especially the time difference between the two groups, as all the NA group horses were anaesthetized previously to the A once. However, a relatively narrow time period for data inclusion was selected, the anaesthesia protocol was identical and all, except one horse, recovered in the same recovery box. Another limitation of our study is the fact that anaesthesia's and consequently evaluation of the recovery phases were done by different veterinarians. Therefore all recoveries from group A were additionally evaluated by a single person using videotapes (MR), without previous knowledge of the scores awarded by the anaesthetist in charge. The scores recorded on the protocols did not vary significantly from the once of MR, and the agreement was good. Unfortunately, no video recordings were available for the NA group. Another limitation of the study might be the limited number of horses. Kaestner (2010) calculated that 47'000 horses would be necessary to show a reduction in risk of fracture from 2/1000 to $1 / 1000$ (power of $80 \%$ ). However, this calculation was done based on data obtained in healthy (ASA I and II) horses. For our population we would need 7650 colic anaesthesia recoveries to determine with a power of $80 \%$ if incidence of fatal injury can be reduced from $3 / 100$ to $2 / 100$ by rope assisted recovery (http://clincalc.com/Stats/ SampleSize.asp).

In conclusion, the present study could not show a benefit of using the head and tail-rope system after colic surgery at our institution. Additionally, possible complications associated to the system could be documented. Hypoxemia during anaesthesia will increase the risk of non-safe recovery. However, prospective randomized large multicentre studies are necessary to provide more evidence for best practice for colic horse recovery.

\section{Conflict of interest}

The authors report no conflict of interest.

\section{References}

Aver U., Huber C. (2012) A comparison of head/tail rope-assisted versus unassisted recoveries of horses after partial intravenous general anaesthesia. Abstracts presented at the Association of Veterinary Anaesthetists Spring meeting, 22nd -23rd March 2012, Davos, Switzerland. Vet. Anaesth. Analg. 40, 3 
Bettschart-Wolfensberger R. (2012) Recovery from anesthesia. In: Equine Surgery, 4th edn., Eds: J. A. Auer, J. A. Stick, Elsevier Saunders, St. Louis, Missouri. pp. 246-253

Bidwell L. A., Bramlage L. R., Rood W. A. (2007) Equine perioperative fatalities associated with general anaesthesia at a private practice a retrospective case series. Vet. Anaesth. Analg. 34, 23-30

Clark-Price S. T. (2013) Recovery of horses from anesthesia. Vet. Clin. North Am. Eq. Pract. 29, 223-242

Del Castillo S., Matthews N. S. (2005) How to assemble, apply, and use a head-and-tail rope system for the recovery of the equine anesthetic patient. Proceedings of the Annual Convention of the American Association of Equine Practitioners, Seattle, Washington, USA, 51, 490-493

Driessen B. (2006) Assisted recovery. In: Manual of Equine Anesthesia and Analgesia, Eds: T. Doherty, A. Valverde, Blackwell Publishing Ltd, Oxford. pp. 338-351

Dugdale A. H. A., Obhrai J., Cripps P. J. (2016) Twenty years later: a single-centre, repeat retrospective analysis of equine perioperative mortality and investigation of recovery quality. Vet. Anaesth. Analg. 43, 171-178

Dugdale A. H. A., Taylor P. M. (2016) Equine anaesthesia-associated mortality: where are we now? Vet. Anaesth. Analg. 43, 242-255

Grandy J. L., Steffey E. P., Hodgson D. S., Woliner M. J. (1987) Arterial hypotension and the development of postanesthetic myopathy in halothan-anesthetized horses. Am. J. Vet. Res. 64, 114-115

Hubbell J. A. E. (2005) Recovery from anaesthesia in horses. Equine Vet. Educ. 7, 45-52

Johnston G. M., Eastment J. K., Wood J. L. N., Taylor P. M. (2002) The confidential enquiry into perioperative equine fatalities (CEPEF): mortality results of phases 1 and 2. Vet. Anaest. Analg. 29, 159-170

Kaestner S. B. R. (2010) How to manage recovery from anaesthesia in the horse - to assist or not to assist? Pferdeheilkunde 26, 604-608

Liechti J., Pauli H., Jäggin N., Schatzmann U. (2003) Untersuchungen zum assistierten Aufstehen von Pferden während der Aufwachphase nach einer Inhalationsanästhesie. Pferdeheilkunde 19, 271-276

Muir W. W., Hubbell J. A. E. (2009) Considerations for inducting, maintenance, and recovery. In: Equine Anesthesia: Monitoring and Emergency Therapy, 2nd edn., Eds: W. W. Muir, J. A. E. Hubbell, Saunders Elsevier, St. Louis, Missouri. pp. 381-396

Richey M. T., Holland M. S., McGrath C. J., Dodman N. H., Marshall D. B., Court M. H., Norman W. M., Seeler D. C. (1990) Equine post-anesthetic lameness, a retrospective study. Vet. Surg. 19, 392-397

Steffey E. P., Wheat J. D., Meagher D. M., Norrie R. D., McKee J., Brown M., Arnold J. (1977) Body position and mode of ventilation influences arterial $\mathrm{pH}$, oxygen, and carbon dioxide tensions in halothane-anesthetized horses. Am. J. Vet. Res. 38, 379-382

Trim C. M., Adams J. G., Cowgill L. M., Ward S. L. (1989) A retrospective survey of anaesthesia in horses with colic. Equine Vet. J. 21, 84-90

Wagner A. E. (2009) Complications in equine anesthesia. Vet. Clin. North Am. Equine Pract. 24, 735-752

Wilderians $H$. (2008) The 1 man rope assisted recovery from anaesthesia in horses. Proceedings of the 10th International Congress of Equine Veterinary Association, Moscow, Russia, 203-205

Young S. S., Taylor P. M. (1993) Factors influencing the outcome of equine anaesthesia: a review of 1,314 cases. Equine Vet. J. 25, 147-151

Erweiterte Zusammenfassung

\section{Vergleich der nicht-assistierten und der assistierten Auf- wachphase mit Kopf- und Schweifseil nach Kolikopera- tion beim Pferd}

Die Allgemeinanästhesie bei Pferden isł gegenüber anderen Spezies mit einem erhöhten Risiko der Mortalität und Morbidität verbunden. Herzstillstand oder kardiovaskulärer Kollaps, Frakturen und Myopathien gelten als Hauptgründe für die Todesfälle. Dadurch wird die Aufwachphase zu einer kriti- schen und schlecht voraussagbaren Phase. Das Fluchtverhalten des Pferdes wird als einer der Hauptrisikofaktoren in der Aufwachphase angesehen, da es oft verantwortlich für verfrühte Aufstehversuche ist. Weiter wird vermutet, dass langes Liegen bei Pferden zu schlechter Durchblutung der Muskulatur und Nervenschädigungen führen kann. Darüber hinaus kann die dämpfende Wirkung der Anästhetika auf mentale, propriozeptive und motorische Funktionen zu Problemen in der Koordination während dem Aufstehen führen. Verfrühte Aufstehversuche kombiniert mit ungenügender Koordination und Muskel- oder Nervenschwäche führen konsequenterweise zu erfolglosen Aufstehversuchen, Stürzen und einem hoher Verletzungsrisiko. Deshalb scheint es sinnvoll, Pferde mit einem hohen Risiko von post-anästhetischen Komplikationen in der Aufwachphase zu assistieren. Zu diesen "Hochrisikopatienten" gehören u.a. Pferde nach Kolikoperationen, bei welchen das Mortalitätsrisiko um ein Vielfaches erhöht ist.

In den letzten Jahren wurden verschiedene Techniken entwikkelt um Pferde in der Aufwachphase nach Allgemeinanästhesien zu unterstützen. Die assistierte Methode mit Kopf- und Schweifseil ist vermutlich die zur Zeit am häufigsten angewendete Methode. Diese Technik ist günstiger als andere assistierte Methoden, einfacher anzuwenden und bietet, verglichen mit dem manuellen Aufstellen, mehr Sicherheit für das Personal. Spezialisten vermuten, dass diese Technik das Risiko der Aufwachphase reduzieren kann, wenn sie von erfahrenem Personal angewendet wird. Aktuell liegen noch nicht genügend wissenschaftliche Daten vor, um die assistierte Methode mit Kopf- und Schweifseil mit nicht-assistierten Aufwachphasen vergleichen zu können. Vor allem Untersuchungen zum Nutzen bei Hochrisikopatienten, wie zum Beispiel den Pferden nach Kolikoperationen, fehlen. An der Vetsuisse-Fakultät der Universität Zürich sind Pferde nach Kolikoperationen bis Ende 2011 unassistiert aufgestanden, ab 2012 assistiert mit Kopfund Schweifseilen.

Ziel dieser Studie war es, unassistierte Aufwachphasen (Gruppe NA) mit assistierten Aufwachphasen mit Kopf- und Schweifseil (Gruppe A) nach Kolikoperation bei Pferden zu vergleichen. Die Pferde hatten alle eine standardisierte Medetomidin-Isofluran balancierte Anästhesie erhalten, sowie Morphium und Medetomidin für die Aufwachphase. Zusätzlich wurden mögliche Risikofaktoren für die Qualität der Aufwachphase eruiert und mögliche Komplikationen im Zusammenhang mit der assistierten Methode mit Kopf- und Schweifseil festgehalten. Dazu wurden 200 Anästhesieprotokolle (100 NA, 100 A) aus dem Zeitraum vom März 2008 bis Dezember 2015 retrospektiv analysiert. Von der assistierten Gruppe waren Videoaufnahmen der Aufwachphasen vorhanden. Diese wurden immer von der gleichen Person (Autor MR) evaluiert und mit dem gleichen Aufwachscore beurteilt, wie sie auch von den Anästhesisten vor Ort verwendet worden waren (1: erster Aufstehversuch erfolgreich, minimale Ataxie, 2: zweiter Aufstehversuch erfolgreich, 3: mehr als 2 Aufstehversuche, Pferd bleibt ruhig, 4: Pferd regt sich auf, Verletzungsgefahr besteht, 5: Aufstehphase resultiert in Verletzung des Pferdes). Für die Analyse der Risikofaktoren wurden die Aufwachscores dichotomisiert (sichere Aufwachphase (S): Score 1-3; nicht-sichere Aufwachphase (NS): Score 4 und 5).

In der vorliegenden Studie konnte kein signifikanter Unterschied zwischen den zwei Gruppen NA und A bezüglich der 
Qualität der Aufwachphase (Score) festgestellt werden (Tabelle 1). S versus NS Aufwachscores waren ähnlich verteilt zwischen den Gruppen A und NA (Grafik 3). Es kam bei beiden Gruppen zu verschiedenen Komplikationen während der Aufwachphase was bei je 3/100 Pferden pro Gruppe zur Euthanasie oder Tod geführt hat. In der nicht-assistierten Gruppe (NA) war bei 1/100 Pferden ein Zwischenfall, der zu einer Humerusfraktur führte der Grund für die Euthanasie. Die anderen 2 Pferde sind gestorben bevor sie aufstehen konnten. Ein Pferd starb nachdem es starke Krämpfe gezeigt hatte und eines nach einem Atemstillstand in der Aufwachboxe. Vier Pferde in der nicht-assistierten Gruppe benötigten am Ende manuelle Hilfe oder Hilfe mit Seilen, da sie ohne diese nicht aufstehen konnten. In der assistierten Gruppe (A) hatte sich bei 3/100 Pferden ein Zwischenfall während er Aufwachphase ereignet, der zu einer Euthanasie geführt hat. Zwei Pferde mussten aufgrund einer Tibiafraktur euthanasiert werden. Ein Pferd musste in Agonie euthanasiert werden, vermutlich aufgrund eines Genickbruches nach einem Sturz in die Wand, nachdem das Kopfseil am Halfter ausgerissen war. Vier Pferde zeigten nicht lebensbedrohliche Probleme (1 leichtgradige Myopathie, 1 Facialisparese, 1 Radialisparese/ Tricepsmyopathie, 1 Schleimhautverletzungen, Exkoriation am Auge und Zahnfraktur).

Neben den oben erwähnten Vorteilen, welche die Methode mit Kopf- und Schweifseil bietet, ist deren Anwendung nicht unproblematisch. So werden diverse Nachteile beschrieben, wie das benötigte ausgebildete Personal, Pferde die gegen die Seile ankämpfen und technische Probleme. Materialversagen, Verdrehen von Seilen, Abfallen von Halftern und sich lösende Seile konnten auch in der vorliegenden Arbeit beobachtet werden. Diese im Zusammenhang mit dem Anwenden der Seile beobachteten technischen Probleme waren möglicherweise mitverantwortlich für die unerwartet hohe Anzahl an gefährlichen und fatalen Aufwachphasen in der Gruppe A.
Ausserdem ist aus Sicht der Autoren die verwendete Aufwachboxe nicht ideal für das Anwenden der Seilmethode und hat mit zu den technischen Problemen beigetragen. Weiter werden Kolikoperationen häufig während der Nacht durchgeführt und dadurch die Pferde in der Aufwachphase durch weniger erfahrenes Personal assistiert. Wir vermuten, dass die Qualität der Aufwachphase mit einer ideal konzipierten Aufwachboxe, hochqualitativem und regelmässig geprüftem Material sowie durch erfahrenes Personal angewendet, verbessert werden kann.

Verglichen wurden auch die Gruppe mit sicheren Aufwachphasen (S) und die Gruppe mit nicht-sicheren Aufwachphasen (NS) (Tabelle 2 und 3). Das Auftreten von Hypoxämie (arterieller Saverstoffpartialdruck $<60 \mathrm{mmHg}$ ) während der Anästhesie war ein Risikofaktor für nicht sichere Aufwachphasen. Keinen signifikanten Einfluss hatte das Alter, das Gewicht, die Anästhesiedaver, der Grund für die Kolikoperation, die Methode der Aufwachphase (A, NA), das Auftreten von Hypotension (mittlerer arterieller Blutdruck $<70 \mathrm{mmHg}$ für $\geq 15$ Minuten) während der Anästhesie, die Zeit in Seitenlage, die Zeit in Brustlage und die Zeit bis zum Stand. Die Aufwachscores (S, NS) in der Gruppe A beurteilt durch die Anästhesisten und die Scores (S, NS) in der Gruppe A beurteilt durch MR waren nicht signifikant unterschiedlich.

Zusammenfassend konnte die vorliegende Studie nicht zeigen, dass durch das Anwenden der assistierten Technik mit Kopf- und Schweifseil Unfälle reduziert oder die Qualität der Aufwachphase nach Kolikoperationen verbessert werden können. Hypoxämie während der Anästhesie erhöht das Risiko für eine schlechte Aufwachphase.

Schlüsselwörter: Aufwachphase, Kopf- und Schweifseil, Pferd, Kolikoperation, Allgemeinanästhesie 